\title{
¿DERECHO A LA FELICIDAD?
}

\author{
A Right to Happiness?
}

\section{Direito À FELICIDADE?}
* $\quad$ orcid.org/0000-0003-2324-8458. Pontificia Universidad Católica de Chile, Chile. jose.tomas.alvarado@gmail.com

RECIBIDO: O5 DE ABRIL DE 2016. ENVÍO A PARES: O3 DE JUNIO DE 2016. APRoBAdo POR PARES: 12 dE AGOSTO DE 2016. ACEPTAdo: 26 DE SEPTIEMBRE DE 2016.

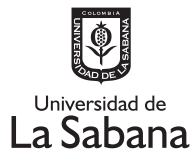

DOI: $10.5294 / D I K A .2016 .25 .2 .5$

PARA CITAR ESTE ARTíCULO / TO REFERENCE THIS ARTICLE / PARA CITAR ESTE ARTIGO Alvarado, José Tomás, “iderecho a la fElicidad?”, en DikaION, 25, 2 (2016), 


\section{RESUMEN}

Se ha propuesto un "derecho a la felicidad" como parte de los derechos humanos de tercera generación. Este trabajo considera de manera crítica la inteligibilidad de tal derecho fundamental. Se argumenta que se puede efectuar una distinción gruesa entre concepciones "internalistas" y "externalistas" de la felicidad. Las concepciones internalistas sostienen que la felicidad requiere de acciones libres. Las concepciones externalistas sostienen que la felicidad puede ser conseguida con independencia de la voluntad de la persona, simplemente por la obtención de ciertos objetos, estados o eventos. Se argumenta que bajo cualquiera de estas interpretaciones, un derecho a la felicidad no tiene sentido. Se alega que es imposible cumplir universalmente con un derecho a la felicidad "externalista", pues el Estado solo puede hacer a alguien "feliz" al costo de la infelicidad de otras personas. Un derecho a la felicidad bajo la interpretación internalista, por otra parte, es también imposible porque no hay nada que pueda hacer un Estado - o un tercero- para reemplazar la actividad libre de una persona.

\section{PALABRAS CLAVE}

Derecho a la felicidad; derechos fundamentales; felicidad; derechos. 


\section{ABSTRACT}

A "right to happiness" has been proposed as part of third generation human rights. This study takes a critical look at the intelligibility of a fundamental right of this sort, arguing that a gross distinction can be made between "internalist" and "externalist" ideas of happiness. Internalist ideas hold that happiness requires free action. Externalist ideas hold that happiness can be achieved independent of the will of the person, simply by obtaining certain objects, circumstances or events. It is argued that a right to happiness makes no sense in light of either of these interpretations, since it is impossible to comply universally with an "externalist" right to happiness. The state can only make someone "happy" at the expense of the happiness of others. Conversely, a right to happiness according to the internalist interpretation is impossible as well, simply because there is nothing a state or a third party can do to replace the free action of a person.

\section{KEYWORDS}

Right to happiness; fundamental rights; happiness; rights. 


\section{RESUMO}

Propôs-se um "direito à felicidade" como parte dos direitos humanos de terceira geração. Este trabalho considera de maneira crítica a inteligibilidade de tal direito fundamental. Argumenta-se que pode ser feita uma grande diferença entre concepções "internalistas" e "externalistas" da felicidade. As concepções internalistas sustentam que a felicidade requer ações livres. As concepções externalistas sustentam que a felicidade pode ser conseguida com independência da vontade da pessoa, simplesmente pela obtenção de certos objetos, estados ou eventos. Argumenta-se que, sob qualquer dessas interpretações, um direito à felicidade não faz sentido. Alega-se que é impossivel cumprir universalmente com um direito à felicidade "externalista", pois o Estado só pode fazer alguém "feliz" ao custo da infelicidade de outras pessoas. Um direito à felicidade sob a interpretação internalista, por outra parte, é também impossivel porque não há nada que possa fazer um Estado - ou um terceiro- para substituir a atividade livre de uma pessoa.

\section{PALAVRAS-CHAVE}

Direito à felicidade; direitos; direitos fundamentais; felicidade. 


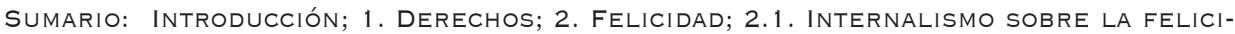
DAD; 2.2. EXTERNALISMO SOBRE LA FELICIDAD; 3. ¿QUÉ SERÍA UN DERECHO A LA FELICIDAD?; 3.1. DERECHO A UNA FELICIDAD EXTERNA A LA VOLUNTAD; 3.2. DERECHO A UNA FELICIDAD INTERNA A LA VOLUNTAD; 4. CONCLUSIONES; BIBLIOGRAFÍA.

\section{INTRODUCCIÓN}

El "derecho a la felicidad" ha sido propuesto como uno de los nuevos "derechos humanos de tercera generación”. En la Revolución francesa se habría postulado la "primera generación" de derechos humanos, contemplando aquellos derechos civiles y politicos que aseguran a las personas un ámbito de autonomía frente al Estado y la capacidad de participar en las deliberaciones públicas. Durante el siglo pasado se habría postulado una "segunda generación" de derechos humanos, ahora de carácter económico y social. Si la primera generación de derechos habria abierto un espacio formal de autonomía para las personas, se trataría ahora de dotar de contenido sustantivo a esa autonomía, garantizando los medios materiales necesarios para su libre despliegue. La "tercera generación" de derechos humanos vendría a llevar este camino de progreso moral, político y jurídico a una nueva etapa. Se trataría ahora no solo de garantizar formalmente y por medios materiales suficientes el despliegue de la propia autonomía, sino de garantizar una buena calidad de vida para las personas. ${ }^{1}$ No solo se debería exigir del Estado la ausencia de coerción inmotivada o la prestación de servicios de salud y educación, sino también - por ejemplo— la protección de los ecosistemas, la paz entre Estados, una vida sexual sin consecuencias no consentidas y acceso a Internet. ${ }^{2}$ Entre la panoplia de nuevas reclamaciones se ha presentado la felicidad o el bienestar subjetivo (subjective well-being). El interés jurídico y político por la felicidad como objeto de una garantía fundamental ha surgido a la par que el interés que han mostrado por ella la psicología empírica y otras ciencias sociales. El bienestar subjetivo se ha tratado de medir. Los indicadores gruesos de desarrollo de un país -el producto geográfico bruto junto, quizás, con el coeficiente de Gini- se han complementado con índices más finos de "desarrollo humano" que incluyen factores hasta ahora desatendidos. No basta con que los Estados procuren crecimiento económico y la redistribución del ingreso. Los Estados deberían ahora ocuparse de la felicidad de las personas. La tercera generación de derechos sería el reflejo político y jurídico de esta evolución. ${ }^{3}$

1 Se ha dicho que si la libertad fue la gran conquista de la primera generación de derechos humanos y la igualdad fue la gran conquista de la segunda generación, esta tercera generación tiene como eje orientador la solidaridad. Antonio-Enrique Pérez LuÑo, La tercera generación de derechos humanos, Cizur Menor, Thomson Aranzadi, 2006, p. 34. Es altamente dudoso, sin embargo, pensar que la garantía de un medio ambiente no contaminado, por ejemplo, implique una mayor solidaridad que la garantía de ciertas prestaciones de salud. Ambas cosas deberían ser aseguradas por el Estado mediante esa forma de solidaridad forzada que son los impuestos.

2 Idem, pp. 25-48.

3 Por ejemplo, se ha pensado que un complemento del análisis económico del derecho es la consideración de las consecuencias de las disposiciones legales y de las adjudicaciones jurídicas en el bienestar subjetivo. Eric A. Posner, Cass R. Sunstein (eds.), Law and Happiness, Chicago, The 
Este trabajo tiene por objetivo examinar con detenimiento el concepto de un derecho a la felicidad. ¿Es siquiera inteligible un derecho subjetivo que tenga como contenido la felicidad o el bienestar subjetivo o algo así? La hipótesis central de este trabajo es que no es realmente inteligible. La felicidad de las personas — contra lo que pueda estar inclinado a sostener la ortodoxia liberal - debe ser el objetivo central de los Estados. La legitimidad moral de un Estado descansa precisamente en la aptitud que tenga para asumir esta tarea. Pero esto no debe verse como la exigencia de un derecho subjetivo fundamental correlativo. Hay una variedad grande de formas de entender qué haya de ser la felicidad, pero bajo cualquiera de estas formas la idea de un derecho cuyo objeto sea la felicidad es, o incoherente, o ininteligible - salvo en un sentido muy restringido en el que consagrar tal derecho seria redundante- - Hemos estado acostumbrados a una retórica política en la que se apela a derechos como las dimensiones definitorias de lo justo y lo correcto. Pero esta retórica tiene limitaciones que se tratarán de mostrar en lo que sigue. Las dimensiones más importantes de la vida humana en sociedad no son dimensiones que se dejen atrapar como derechos de los que tenga sentido decir que han sido otorgados, negados, respetados o violados.

En lo que sigue se va a tratar, en la sección primera, qué es lo que debe entenderse por un derecho y por un derecho fundamental. En la sección segunda se va a considerar qué es lo que debe entenderse por felicidad; se trata de una cuestión filosóficamente muy sustantiva por lo que no se pretende ofrecer aquí respuestas muy definitivas, sino simplemente presentar grandes alternativas relevantes para la cuestión en liza. En la tercera sección, por último, se va a atacar directamente el problema central, considerando qué contenido jurídico podría asignarse a un eventual derecho a la felicidad.

\section{DERECHOS}

Se hace necesario iniciar este examen con algunas precisiones mínimas respecto de qué debe entenderse por un derecho y por un derecho fundamental. El esquema más utilizado para comprender los derechos subjetivos es el propuesto por Wesley Hohfeld, ${ }^{4}$ quien distingue cuatro tipos básicos de incidentes (Hohfeldian incidents) o elementos: libertades (también denominados "privilegios"), reclamos / derechos ${ }^{5}$ (claims), poderes e inmunidades. ${ }^{6}$ Se va a seguir aquí este esquema en el que los incidentes hohfeldianos pueden ser definidos del siguiente modo:

University of Chicago, 2010; John Bronstein, Christopher Buccafusco, Jonathan S. Masur (eds.), Happiness and the Law, Chicago, The University of Chicago Press, 2015.

4 Wesley N. Hohfeld, "Some fundamental legal conceptions as applied in judicial reasoning", Yale Law Journal 23 (1913). Reimpreso en Fundamental Legal Conceptions as Applied in Judicial Reasoning and Other Legal Essays. Walter Wheeler Cook (ed.), New Haven, Yale University Press, 1923, pp. 23-46.

5 La expresión "reclamo/derecho" puede resultar extraña, pero la traducción más cercana del término claim sería simplemente "derecho". Como Hohfeld sostiene que los cuatro elementos son constituyentes de los derechos (rights) conviene fijar una expresión específica para designar a un claim y diferenciarlo de un right.

6 Cfr. para presentaciones de este esquema Carl Wellman, An Approach to Rights. Studies in Philosophy of Law and Morals, Dordrecht, Springer, 1997, pp. 1-48; William A. Edmundson, An Introduction 
[Definición 1] $\quad A_{1}$ tiene el reclamo/derecho de que $A_{2}$ haga $\phi={ }_{\mathrm{df}} A_{2}$ tiene la obligación de hacer $\phi$ a favor de $A_{1}$.

Fácilmente se puede ver que los reclamos son relaciones conversas de las obligaciones. ${ }^{7}$ Se han notado varias limitaciones en esta idea de reclamo / derecho que no son relevantes para el examen de este trabajo. ${ }^{8}$

[Definición 2] $\quad A_{1}$ tiene la libertad de hacer $\phi=\mathrm{df}$ No hay ninguna persona $A_{2}$ tal que: $A_{2}$ tiene el reclamo / derecho de que $A_{1}$ haga $\phi$.

[Definición 3] $\quad A_{1}$ tiene el poder de que $A_{2}$ haga $\phi={ }_{\mathrm{df}} A_{1}$ tiene la capacidad de hacer que $A_{2}$ tenga la obligación de hacer $\phi$ a favor de algún $A_{3}$.

Así como hay un poder para establecer una obligación y el reclamo / derecho correlativo, también hay poderes para establecer libertades, poderes e inmunidades. Un poder es de manera general la capacidad de modificar cualquiera de los elementos hohfeldianos.

[Definición 4] $\quad A_{1}$ tiene una inmunidad respecto de $A_{2}$ y la acción $\phi={ }_{\mathrm{df}} A_{2}$ no tiene el poder de hacer que $A_{1}$ tenga la obligación de hacer $\phi$ a favor de algún $A_{3}$.

De acuerdo con la Definición 4, una inmunidad es la contradictoria de un poder. Los poderes y las inmunidades son de segundo orden pues su objeto no son directamente acciones o tipos de acciones -que son el objeto de los reclamos / derechos y las libertades - sino que son obligaciones y libertades. Las normas que fundan poderes e inmunidades deberian considerarse, por tanto, como reglas secundarias, esto es, como reglas que tienen por objeto otras reglas. ${ }^{9}$

to Rights, Cambridge, Cambridge University Press, 2004, pp. 87-102; F. M. Kamm, "Rights", en Jules L. Coleman, Kenneth Einar Himma, Scott J. Shapiro (eds.), The Oxford Handbook of Jurisprudence and Philosophy of Law, Oxford, Oxford University Press, 2004, pp. 476-513; Alon Harel, "Theories of Rights", en Martin P. Golding, William A. Edmundson (eds.), The Blackwell Guide to the Philosophy of Law and Legal Theory, Oxford, Blackwell, 2005, pp. 191-206; George W. RAInBolt, The Concept of Rights, Dordrecht: Springer, 2006, pp. 1-23; Robert Alexy, Teoría de los derechos fundamentales, traducción y estudio introductorio de Carlos Bernal Pulido, Madrid, Centro de Estudios Políticos y Constitucionales, 2007, pp. 173-185; Duncan Ivison, Rights, Stocksfield: Acumen, 2008, 10-13; Leif Wenar, "The Analysis of Rights" en Matthew H. Kramer, Claire Grant, Ben Colburn, Antony HAtzistavrou (eds.), The Legacy of H. L. A. Hart: Legal, Political, and Moral Philosophy, Oxford, Oxford University Press, 2008, pp. 251-274; Leif Wenar, "Rights", en Ed ZaLTA (ed.), The Stanford Encyclopedia of Philosophy, 2015, en http://plato.stanford.edu/entries/rights/, fecha de consulta: 30 de septiembre de 2015; John FinnIs, Natural Law and Natural Rights, 2 ed., Oxford, Clarendon Press, 2011, pp. 198-230.

$7 \quad$ De una manera general la conversa de una relación asimétrica $R x y$ —esto es, la relación $R$ entre los objetos $x$ e $y$ - es la relación $R^{*} y x$. Si $R$ es una relación asimétrica, entonces si $x$ está en la relación $R$ con $y$, entonces $y$ no está en la relación $R$ con $x$. Por ejemplo, la conversa de ' $A_{1}$ es padre de $A_{2}$ ' es ' $A_{2}$ es hijo de $A_{1}$ '.

8 John Finnis, Natural Law and Natural Rights, op. cit., pp. 201-204.

9 H. L. A. Hart, The Concept of Law, Second Edition with a Postcript, Penelope A. Bulloch, Joseph Raz (eds.), Oxford, Clarendon Press, 1994, pp. 94-99. 
Se ha sostenido que un derecho subjetivo debe entenderse como un conjunto de elementos hohfeldianos del tipo presentado aquí. Por ejemplo, se podría sostener que el derecho de propiedad de $A_{1}$ sobre el bien $x$ es un complejo de diferentes elementos hohfeldianos. En primer lugar, la libertad para usar y gozar de $x$, lo que se debe entender, de acuerdo con la Definición 2, como el hecho de que $A_{1}$ no tiene ninguna obligación de entregar $x$ a alguien o permitir a alguien gozar de $x$-diferente de $A_{1}$, por supuesto-. El hecho de que uno no esté obligado a entregar $x$ a alguien, sin embargo, no serviría para garantizar el uso y goce pacífico de $x$ si a cualquiera le estuviese permitido interferir en ese uso y goce. La propiedad sobre $x$, entonces, debe ir acompañada de un reclamo/derecho de $A_{1}$ respecto de toda otra persona para que tal persona no haga cualquier acción que sea una perturbación del uso y goce de $x$. Por otro lado, uno podría tener la libertad de usar y gozar $x$ sin poder transferir esta libertad a nadie. Es un componente de un derecho de propiedad sobre $x$, por tanto, el poder de ceder el uso y goce de $x$. Esto es lo que hace un propietario cuando entrega su propiedad en arrendamiento o comodato, cuando la vende o la dona, o cuando constituye un usufructo a favor de otra persona. Pero estos no son todos los elementos hohfeldianos que pueden ser discriminados como componentes del derecho de propiedad. Por ejemplo, el artículo 19, núm 24, inc. 2 de la Constitución de la República de Chile (en adelante CPR) señala que solo una ley puede establecer las limitaciones y obligaciones que deriven de la función social de la propiedad. El inciso 3 del mismo numeral establece que nadie puede ser privado de su propiedad sino en virtud de ley general o especial que autorice la expropiación por causa de utilidad pública o de interés nacional. Resulta, entonces, que es parte del contenido del derecho de propiedad una inmunidad respecto de los actos de cualquiera otra persona que no sea el legislador que pretendan modificar las libertades, reclamos / derechos o poderes indicados. Sin esta inmunidad difícilmente podría $A_{1}$ usar y gozar de $x$, pues cualquiera tendría el poder de modificar sus libertades - estableciendo, por ejemplo, la obligación de que $A_{1}$ entregue $x$ a un tercero- o sus reclamos / derechos al eximir a alguien de su obligación de no perturbar el uso y goce pacífico de $x$.

Cuando se ha propuesto un derecho a la felicidad se está pensando en un derecho de carácter "fundamental". Esto implica varias especificaciones adicionales que conviene tener en cuenta. ${ }^{10}$ Un derecho fundamental ha sido caracterizado como un derecho que corresponde a todos los seres humanos dotados del estatus de persona. ${ }^{11}$ Se trata de derechos no patrimoniales. No pueden, por ello, ser transados o cedidos. Nadie puede, tampoco, renunciar a ellos. Los derechos fundamentales desde el punto de vista del esquema de Hohfeld implican, por un lado, poderes restringidos y, por otro, inmunidades expandidas. En primer lugar, un

10 Luigi Ferrajoli, "Diritto fondamentali”, en Teoria Politica 14 (2) (1998), pp. 3-33. Reimpreso como "Derechos fundamentales", en Antonio Cabo, Gerardo Pisarello (eds.), Los fundamentos de los derechos fundamentales, Madrid, Trotta, 2001, pp. 19-56; L. FERRAJOLI, "I fondamenti dei diritti fondamentali", Teoria Politica 16 (3) (2000), pp. 41-113. Reimpreso como "Los fundamentos de los derechos fundamentales”, en A. CaBo y G. Pisarello (eds.), ibid., pp. 287-381.

$250 \quad 11$ Ferrajoli también sostiene que son derechos fundamentales los que se otorgan a todos los ciudadanos o a todos quienes tienen capacidad de obrar. Cfr. L. FERRAJOLI, "Derechos fundar
op. cit., p. 19. No se van a considerar estas otras formas de derechos fundamentales. 
derecho fundamental incluye menos poderes que un derecho patrimonial ordinario, pues nadie tiene el poder de modificar los reclamos / derechos y las libertades implicados en él. Nadie puede, por ejemplo, ceder su propia libertad personal o su vida. En virtud del derecho a la vida toda persona tiene el reclamo / derecho respecto de toda otra persona para que no realice acciones que atenten contra su vida. En virtud del mismo derecho, toda persona tiene la libertad consistente en no estar obligada a entregar su vida a favor de otra persona. Sucede, sin embargo, que este conjunto de reclamos / derechos y libertades no pueden ser modificados por el titular del derecho. Nadie, por tanto, tiene el poder de obligarse a entregar la propia vida a favor de otro, ni de eximir a otro de su obligación de no realizar acciones que atenten contra la propia vida. Un derecho de carácter patrimonial típicamente incluye el poder de modificar los reclamos / derechos y libertades asociados a él. Si, por ejemplo, alguien posee un crédito - esto es, el derecho de exigir de otra persona el pago de una suma de dinero- el reclamo / derecho puede ser transferido por cesión o puede ser condonado. Los derechos fundamentales traen también aparejadas mayores inmunidades que las asociadas a un derecho patrimonial cualquiera. Normalmente, los derechos fundamentales son establecidos por normas constitucionales o por tratados internacionales. ${ }^{12}$ Los reclamos / derechos, libertades y poderes que se posean en virtud de un derecho fundamental no pueden ser modificados por nadie que no sea el poder constituyente o el poder soberano de varios Estados que suscriben un tratado.

\section{FELICIDAD}

Si la felicidad ha de ser el objeto de un derecho fundamental, es crucial tener mayor claridad acerca de qué sea. Esta es una cuestión extremadamente delicada. Para los propósitos de este examen se hará una presentación esquemática de un par de grandes alternativas que deberian tenerse en consideración. La presentación de estas dos alternativas, aunque esquemática, servirá para aclarar los aspectos que presentan más problemas de un supuesto derecho fundamental a la felicidad en la medida en que se trata de alternativas lo suficientemente amplias como para cubrir la multitud de concepciones más específicas.

El término "felicidad" se utiliza de diferentes modos. Hay, en primer lugar, una amplia gama de usos lingüísticos en los que felicidad designa algo opuesto psicológicamente a la depresión. Bajo el rótulo de "felicidad" pueden caer el placer, el nivel de satisfacción que pueda tener una persona con su propia vida, un estado emocional positivo o cierto estado de afirmación psíquica. ${ }^{13}$ También, sin embargo, se ha utilizado el término "felicidad" como algo poseedor de un carácter normativo, como la vida buena, esto es, la vida digna de ser vivida y bien vivida. O, si se sigue una metáfora vegetal, como el florecimiento de un ser humano. Esta paleta

12 Respecto de los derechos humanos, por lo demás, se ha sostenido que forman parte del ius cogens, esto es, el ordenamiento que obliga a todos los Estados aun sin su consentimiento.

13 Daniel M. HayBron, The Pursuit of Unhappiness. The Elusive Psychology of Well-Being, Oxford, Oxford University Press, 2008, pp. 61-154; Giuseppe AвḂ̇, Felicidad, vida buena y virtud, Barcelona, Ediciones Internacionales Universitarias, 1992, pp. 27-30. 
de alternativas ofrece un espectro amplísimo. Es bien conocido que para una larga tradición de corrientes de filosofía moral la felicidad es el fin último de toda vida humana. Todo acto humano es bueno en la medida es que sea apto para generar la felicidad o pueda ser integrado coherentemente en una vida feliz. Hay otras corrientes de filosofia moral, sin embargo, para las que la felicidad es algo ajeno a la moral propiamente tal. Se trataría de un tipo de motivación que se puede constituir en un obstáculo para que los sujetos actúen de un modo moralmente recto.

Una primera distinción gruesa que podría hacerse aquí es entre concepciones de la felicidad como algo dotado de un carácter normativo y las concepciones normativamente neutrales. Tal como se ha indicado, un espectro de concepciones de la felicidad la identifican con la vida buena, y una vida buena es el tipo de vida que uno debe vivir. Una vida buena puede no coincidir con muchos estados psicológicos de contentamiento, con emociones positivas o con placer abundante. Por supuesto, uno puede sostener, por ejemplo, que una vida es mejor en este sentido normativo si es que hay más placer y menos dolor, pero no es necesario que sea así. Hay otro espectro de concepciones de la felicidad en que esta es algo normativamente neutral, ya sea porque se sostenga de un modo general que la ley moral no tiene que ver con la felicidad, o ya sea porque se trata de una especificación de qué sean las emociones, estados psicológicos o qué sea el sentido de satisfacción con la propia vida, sin interesar si estos estados son o no normativamente relevantes desde el punto de vista moral.

Una segunda distinción gruesa, esta vez entre las concepciones de la vida buena con contenido normativo, es la que se hace entre el hedonismo, las teorias de satisfacción de preferencias y las teorias de listas objetivas. ${ }^{14}$ Las teorias hedonistas son aquellas que postulan como bien último el placer y como mal último el dolor. Este tipo de posición fue la adoptada por el utilitarismo clásico. En las teorias de satisfacción de preferencias una vida buena es aquella en la que se satisfacen un mayor número de preferencias del sujeto. Estas preferencias pueden incluir la obtención de placer, pero también el desarrollo de actividades que estén dotadas de un sentido especial o el cultivo de relaciones humanas de una calidad intrínseca. Se supone que a cada agente puede asignarse una función de utilidad que correlaciona cada objeto $\mathrm{u}$ actividad a un grado de satisfacción. Las diferentes formas de liberalismo han tendido a preferir teorias de la vida buena de este tipo, pues son neutrales respecto de qué contenido tengan las preferencias de las personas. Una vida humana buena y floreciente es simplemente aquella en la que un gran número de preferencias han sido realizadas. No interesa cuál sea el contenido de tales preferencias. Del mismo modo, para diversas formas de consecuencialismo, lo que debe ser maximizado en las decisiones personales y en las sociales es la mayor satisfacción del mayor número de personas. Las teorias de listado objetivo, por otro lado, son las que postulan ciertos tipos precisos de bienes humanos básicos de tal modo que una vida humana buena y floreciente ha de consistir en

14 Roger CRISP, "Well-Being” en Ed ZAlTa (ed.), Stanford Encyclopedia of Philosophy, 2013, § 4, en http://plato.stanford.edu/entries/well-being/, fecha de consulta: 10 de octubre de 2015; William Frankena, Ethics, 2 ed., Englewood Cliffs: Prentice Hall, 1973, pp. 79-94. 
la participación en tales bienes. En las teorias de listado objetivo se supone que, normalmente, la participación en los bienes humanos objetivos trae consigo cierta satisfacción, pero no cualquier preferencia es digna de ser satisfecha. Hay preferencias que pueden ser lesivas para el bien humano y que no están realmente en el interés de quien las tiene. Así, en teorías de este tipo puede suceder que un sujeto ignore lo que verdaderamente son sus intereses.

Formas de la teoría del listado objetivo son varias teorías clásicas de la felicidad. Así, para Aristóteles, el bien humano es la "actividad del alma conforme a la virtud". ${ }^{15}$ La virtud es la excelencia en la operación propiamente humana. La eudaimonía tiene que ver, por tanto, con el despliegue de nuestra naturaleza, con el cumplimiento de la función propia (érgon) de un ser humano. Los estoicos sostuvieron que la felicidad - el fin final- es vivir en coherencia con la naturaleza, lo que es equivalente en su concepción a vivir en conformidad con la virtud. ${ }^{16}$ San Agustín sostuvo que la felicidad es gaudium de veritate, ${ }^{17}$ esto es, el gozo que acompaña la contemplación de la verdad, que se identifica con Dios mismo. Santo Tomás de Aquino, siguiendo la tradición agustiniana, sostiene que la felicidad (beatitudo) del hombre es una operación del intelecto especulativo consistente en la contemplación de la esencia divina - ultima et perfecta beatitudo non potest esse nisi in visione divinae essentiae. ${ }^{18}$ Es una operación del intelecto de contemplación teorética - lo que es una cierta actividad del alma - pero cuyo objeto es algo externo al alma, la esencia divina. Hay también varias corrientes contemporáneas que postulan concepciones de la felicidad en la línea general de estas teorías clásicas. ${ }^{19}$ Se ha sostenido, por ejemplo, que una vida buena ha de estar constituida por la participación en bienes o valores humanos básicos tales como el conocimiento, la vida, la experiencia estética, el juego, el amor y la amistad, la sabiduría práctica y la religión. ${ }^{20}$ La participación en cualquiera de estos bienes requiere la actividad del alma tal como lo ha señalado Aristóteles.

Como se ha indicado más arriba, no es posible pretender aquí adjudicar este conjunto de cuestiones de un modo razonable. Lo que sí se puede hacer es tratar de domeñar esta multitud de posiciones de un modo que resulte útil para lo que se examina en este trabajo. Convendrá diferenciar, para estos propósitos, entre i) teorías en las que la felicidad está constituida por actos libres de la persona, y ii) teorías en las que la felicidad puede estar constituida por estados, eventos $u$ objetos externos a la decisión libre de la persona. Para abreviar, se denominará

15 Aristóteles, Ética a Nicómaco I, 7, 1098a 16-17: psychês enérgeia gínetai kat' aretén.

16 Marcelo Boeri, Los estoicos antiguos, traducción, análisis y notas de Marcelo D. Boeri, Santiago, Editorial Universitaria, 2004, pp. 24-30.

17 San Agustín, Confesiones, traducción, notas e introducción de Gustavo A. Piemonte, Buenos Aires, Colihue, 2006, X, p. 23.

18 Santo Tomás de Aguino, Summa theologiae, cura et studio Petri Caramello cum texto ex recensione leonina, Roma, Marietti, 1952, I-II, p. 4.

19 Richard Kraut, What is Good and Why, Cambridge, Harvard University Press, 2007; Thomas Hurka, Perfectionism, New York, Oxford University Press, 1993, pp. 9-51. Para una visión crítica, D. HaYBRON, The Pursuit of Unhappiness, op. cit., pp. 155-196.

20 John FinNis, Natural Law and Natural Rights, op. cit., pp. 59-133; Fundamentals of Ethics, Washington, Georgetown University Press, 1983, pp. 26-55. 
a las teorías del tipo i) como teorías "internalistas" de la felicidad, mientras que a las teorias del tipo ii) se las denominará como teorias "externalistas" de la felicidad.

\subsection{Internalismo sobre la felicidad}

Lo esencial para una posición internalista de la felicidad es que depende completamente del ejercicio de la propia libertad de la persona. La felicidad es algo que se encuentra dentro del alcance de su poder de decisión libre. Esto implica, por un lado, cierta accesibilidad de la felicidad desde la perspectiva de primera persona de cada uno. Implica, sin embargo, también cierta inaccesibilidad de la felicidad para todos quienes no tengan esa perspectiva de primera persona. Una concepción internalista no impide que existan ciertas circunstancias fuera del poder de decisión de una persona que sean necesarias para que la decisión libre pueda ser ejercida. Nadie puede tener amigos si no existen otros seres humanos con los que uno pueda comunicarse. No obstante, alguien podría no tener amigos a pesar de estar rodeado de otros seres humanos si es que se encuentra mal dispuesto hacia todas esas personas - o un aristotélico diria, si es que esas personas no son dignas para entablar una amistad, por carecer de virtud-. Tener amigos requiere de circunstancias externas a la voluntad favorables - la cercanía de un prójimo, la buena voluntad de otra persona con la que se va a entablar una amistad-, pero fundamentalmente de la libre acción de la persona para entablar amistades. La contemplación teorética de la verdad, por otra parte, es típicamente un acto del entendimiento, pero se trata de un acto que la persona debe querer realizar libremente. Algo análogo sucede con las experiencias estéticas o religiosas. Los bienes humanos en los que uno debe participar para ser feliz en una concepción internalista son bienes que se alcanzan por la operación de nuestra propia autonomía. Se trata de concepciones, por tanto, en las que nadie puede ser feliz por otra persona. Nadie puede llegar a ser feliz por representación o de modo vicario por la felicidad de otros. ${ }^{21}$

Las teorías clásicas caen -en términos generales- en esta categoría. Por ejemplo, la actividad del alma de acuerdo con la virtud para la realización de la función propia de una persona humana es actividad voluntaria. También la visión teorética de la divina esencia ha de ser objeto de volición por parte de la persona. ${ }^{22}$ Pero no solamente las teorías clásicas y las que siguen su tradición entran aquí.

21 Lo que no impide, tampoco, que la felicidad de alguien se vea frustrada por la infelicidad de sus amigos o de aquellos a los que ama. La felicidad ajena puede ser un requerimiento necesario para que uno sea feliz, pero no es suficiente. Así como la felicidad de los amigos es una condición para la propia felicidad, la felicidad de otros puede ser ocasión de infelicidad para un envidioso.

22 Hay varias complejidades aquí que no obstan al carácter voluntario de la contemplación de la divina esencia. En primer lugar, de acuerdo con Santo Tomás de Aquino, el entendimiento humano es incapaz por sí mismo de tal acto de contemplación directo, por lo que se requiere un auxilio especial de Dios para permitirlo denominado la lumen gloriae, esto es, una luz sobrenatural que hace visible para un intelecto finito la infinitud de la esencia divina (cfr. Summa theologiae, I, q. 12). La lumen gloriae es un requerimiento necesario externo a la voluntad. No basta por sí sola para la beatitudo pues se requiere la contemplación voluntaria de la persona. En segundo lugar, los bienaventurados no pueden no querer voluntariamente la contemplación de la divina esencia (cfr. Summa theologiae, I, q. 82, a.1). Se trata de una acción libre, que está plenamente en el poder de la persona que la realiza, pero no hay posibilidades abiertas de que no la realice. Esto supone 
Puede ser parte de las preferencias de una persona el desarrollar cierta actividad de forma autónoma. Si uno sostiene de un modo general que la felicidad consiste en la mejor satisfacción de las funciones de utilidad, entonces parte de esa satisfacción va a requerir el libre despliegue de la actividad de los sujetos.

Hay, como se sabe, un complejo debate acerca de la naturaleza de la libertad. ${ }^{23}$ Se ha sostenido que uno solo es libre para decidir realizar la acción $\phi$ si es que uno podría no haber realizado tal acción. Esto es, la acción libre presupone la existencia de posibilidades abiertas. Toda una corriente alternativa, sin embargo, ha sostenido que no se requiere tal cosa. Todo lo que se necesita para que una acción sea una decisión libre - de acuerdo con esta posición- es que haya sido querida por el agente. El hecho de que el agente no haya tenido otras alternativas abiertas no impide que la decisión sea suya y se encuentre bajo su control. De acuerdo con las primeras teorias, la libertad es incompatible con el determinismo; de acuerdo con las segundas, la libertad sí es compatible con este. No es necesario que aquí se adopte una posición acerca de estas cuestiones. Aunque mis simpatías están con las teorias incompatibilistas de la libertad, basta para el examen que se pretende hacer en este trabajo una concepción de la libertad compatibilista. Todo lo que se exige es que la felicidad dependa de las decisiones libres de las personas, esto es, de decisiones que pueden ser imputadas a esas personas como a su agente y que se encuentran bajo su control. No es relevante la existencia o no de posibilidades abiertas a las decisiones tomadas. ${ }^{24}$

\subsection{Externalismo sobre la felicidad}

En las concepciones externalistas, la felicidad esta está constituida por estados, eventos u objetos que no dependen de la decisión voluntaria del sujeto. Por supuesto, alguien puede deliberadamente realizar acciones que conduzcan a la obtención de tales estados, eventos u objetos. La cuestión es que tales estados, eventos u objetos no son decisiones libres. Caen en esta categoría las teorias hedonistas en las que la felicidad es el mayor placer y el menor dolor. Uno puede libremente planear alcanzar placeres y evitar dolores, pero estos placeres y dolores podrían ser generados de un modo completamente externo a la persona. Siguiendo el conocido experimento mental propuesto por Nozick, ${ }^{25}$ alguien podría ser puesto a flotar en una tina y ser conectado a una supercomputadora que genere solamente experiencias placenteras. Uno podría querer conectarse

una concepción compatibilista de la libertad, lo que no es contradictorio con el internalismo sobre la felicidad, tal como se explicará.

23 Robert Kane, "Introduction: The Contours of Contemporary Free Will Debates", en Robert Kane (ed.), The Oxford Handbook of Free Will, Oxford, Oxford University Press, 2002, pp. 3-41.

24 Es más, se ha sostenido por los críticos de las posiciones incompatibilistas o libertarias que la existencia de posibilidades abiertas impediría que la acción pueda encontrarse bajo el control del agente y, con ello, impediría que la acción pueda ser concebida como libre. Si no importando qué antecedentes causales tenga la acción, siempre es posible que la acción no se realice, entonces pareciera que la acción no puede atribuirse al agente sino al azar o la suerte. Para una discusión de este tipo de objeción, véase Peter van Inwagen, "Free Will Remains a Mystery", en R. Kane (ed.), The Oxford Handbook of Free Will, op. cit., pp. 158-177.

25 Robert Nozick, Anarchy, State, and Utopia, Oxford, Blackwell, 1974, pp. 42-45. 
voluntariamente a esta máquina, pero también podría suceder que alguien fuese conectado sin su voluntad o contra su voluntad. Alguien podría planear cuidadosamente un curso de acción para conseguir placer y salir mal de manera que - contra su voluntad - sufra grandes dolores. Alguien podría no haber planeado nada y resultar simplemente afortunado de manera que reciba muchas experiencias placenteras.

También caen en esta categoría teorías que identifican la felicidad con la satisfacción de preferencias. Si las preferencias son del tipo adecuado, entonces su satisfacción sería alcanzar estados, eventos u objetos que resultan externos a la decisión libre de la persona. Si alguien, por ejemplo, tuviese como preferencia acumular el mayor poder sobre otras personas, entonces se podría satisfacer esta preferencia simplemente otorgándole poder. El ejercicio del poder requiere la operación de la voluntad, pero uno puede llegar a tener poder sin ejercerlo. Alguien podría llegar a tener poder sin haberlo buscado voluntariamente, por casualidad o (mala) fortuna. Alguien podría llegar a tener mucho poder sin saber que lo posee. El hijo único de un gran rey podría ser el sucesor al trono sin saber que es el sucesor al trono. Podria haber sido coronado in absentia y no saber que es rey. Puede haber otras preferencias, por supuesto, que caigan en la categoría internalista, pero otras muchas no. La riqueza, el poder, la buena fama, la belleza o la inteligencia son bienes externos a la voluntad y podrían ser conferidos a alguien incluso sin su consentimiento o contra su consentimiento.

\section{3. ¿QUÉ SERÍA UN DERECHO A LA FELICIDAD?}

Consideradas estas grandes alternativas acerca de cómo puede ser comprendida la felicidad conviene examinar directamente el problema central de este trabajo. ¿Es inteligible un derecho subjetivo fundamental a la felicidad? Tal como se ha explicado más arriba, un derecho subjetivo debe ser un complejo de elementos hohfeldianos. Si se trata de un derecho fundamental debe excluir poderes para renunciar, ceder o transferir los reclamos / derechos, libertades, otros poderes e inmunidades en que consista. Debería ser también un derecho de rango constitucional o supraconstitucional, lo que implica inmunidades extendidas para lo que pueda pretender establecer el legislador, una autoridad administrativa $\mathrm{u}$ otras personas. Dada la variedad de concepciones de la felicidad, la configuración que tenga un derecho subjetivo fundamental a la felicidad será también muy variada. De acuerdo con la distinción entre concepciones internalistas y externalistas de la felicidad pueden ser propuestas también dos grandes configuraciones que podría tener el derecho a la felicidad. Esta división es exhaustiva, pues o bien la felicidad consiste en decisiones libres o bien no consiste en decisiones libres. Cualquier derecho a la felicidad - por vaga que sea su formulación - tendrá que ser el derecho a estados, eventos u objetos externos a la voluntad o a estados, eventos u objetos internos a esta, es decir, que tengan como constituyente intrínseco el libre ejercicio de la voluntad de la persona. Se partirá considerando el segundo caso. 


\subsection{Derecho a una felicidad externa a la voluntad}

Podría uno admitir un derecho a una felicidad externa a la voluntad, pues hay prestaciones que inteligiblemente podría dar el Estado para satisfacer tal derecho a una persona. El problema aquí es que este derecho no puede ser satisfecho como derecho subjetivo fundamental para todas las personas. En una concepción de este tipo, la felicidad ha de consistir en el placer y en evitar el dolor; o en cosas tales como el poder, la fama, la riqueza, la belleza o la inteligencia. Un derecho subjetivo a la felicidad debería ser entendido, al menos en lo básico, como un derecho precisamente a obtener tales estados, eventos u objetos.

¿Cuál sería la estructura de tal derecho subjetivo? En primer término debería incluir el reclamo / derecho respecto del Estado para las prestaciones necesarias a fin de conseguir lo que quiera que sea en que - se crea que-consista la felicidad. El Estado tendrá la obligación, por ejemplo, de dar placer y atenuar el dolor. Tal vez podría solventar esta obligación introduciendo a la población en una máquina de experiencias tal como lo ha descrito Nozick. Tal vez podría hacerlo entregando una droga de manera gratuita. Según las preferencias de que se trate, el Estado podria estar obligado a satisfacer otras prestaciones, tales como cirugias estéticas masivas para hacer que todos tengan belleza, o capacidad adquisitiva masiva, o empoderar masivamente a todas las personas, o intervenir en los cerebros para potenciar la inteligencia. Hay muchos problemas con hipótesis como estas desde el punto de vista práctico. Ningún Estado podría hoy día entregar todas estas prestaciones de manera universal. Se trata, sin embargo, del mismo tipo de problemas que han afectado ya a los derechos humanos de segunda generación. También hoy día, gran parte de los Estados carece de los medios para entregar educación o salud a todas las personas. Uno podría suponer, sin embargo, que a pesar de todo sería posible que un Estado pueda entregar prestaciones de estas clases a las personas.

Un derecho subjetivo fundamental de este tipo requeriria no solo el elemento hohfeldiano de un reclamo / derecho o de un conjunto de reclamos/derechos respecto del Estado. Sería indispensable también la libertad de no tener la obligación respecto de otras personas de entregar o dar aquello que se supone que es constitutivo de la felicidad. No serviría de nada si el Estado entrega drogas para provocar placer si luego uno estuviese en la obligación de entregarlas a otros. También debería incluirse un reclamo / derecho respecto de todas las otras personas para que no perturben la felicidad propia. Como se trata de un derecho fundamental debe ser otorgado universalmente a todas las personas y debe incluir inmunidades respecto del legislador, de las autoridades administrativas y de otras personas. Nadie que no sea el constituyente o el poder soberano de varios Estados que suscriban un tratado internacional podría modificar el reclamo / derecho para obtener las prestaciones de que se trate. ${ }^{26} \mathrm{En}$ un derecho fundamental se restringen

26 En general, se tiende a pensar que los derechos humanos son parte del ius cogens, el derecho al que deben someterse los Estados aun sin su consentimiento. Si el derecho a la felicidad fuese 
los poderes para ceder, donar o transferir el objeto del derecho. Normalmente, los derechos fundamentales son irrenunciables. Aquí, sin embargo, no parece muy claro que tenga sentido que las prestaciones o sus objetos sean intransferibles o irrenunciables. Si, por ejemplo, lo que se exige es que el Estado entregue poder adquisitivo, ¿qué podría uno hacer con tal poder adquisitivo sino transferirlo precisamente para intercambiarlo por otras cosas? Un poder adquisitivo intransferible no sería ya más poder adquisitivo. O, para considerar otro ejemplo, ¿por qué no podría transferir mi derecho a una cirugía estética a otra persona? ¿O por qué no podría transferir mi cuota de drogas?

El problema más serio de un derecho subjetivo fundamental a la felicidad entendido de este modo es que generaría conflictos irresolubles. Supóngase que $A_{1}$ tiene ciertas preferencias - constitutivas de su felicidad-que incluyen el poder sobre $A_{2}$. Y $A_{2}$ tiene ciertas preferencias - constitutivas de su felicidad-que incluyen el poder sobre $A_{1}$. Solo se puede conceder poder a $A_{1}$ si se le quita a $A_{2}$ y al revés, solo se le puede conceder poder a $A_{2}$ si se le quita a $A_{1}$. Entonces, no hay ninguna forma de satisfacer las preferencias de uno sin lesionar las preferencias del otro. Frente a problemas de esta clase es frecuente que se postule algún punto de equilibrio entre las diferentes preferencias. La prestación que debería ofrecer un Estado sería entregar, por ejemplo, la mayor cuota de poder compatible con un poder equivalente para todas las personas. Pero esto no sería satisfacer esas preferencias. Quien aspira al poder como constitutivo fundamental de la felicidad pretende precisamente la capacidad de modificar el estatus de todos los demás y la inmunidad para que su estatus sea modificado. Entregar porciones alícuotas de poder a todas las personas es no entregar poder a ninguna de ellas. Uno podría sostener que es injusto que la felicidad de una persona, sea $A_{1}$, se pueda conseguir solo al precio de la felicidad de otra, sea $A_{2}$. Pero lo mismo podría sostener $A_{1}$. Si la función de utilidad de $A_{1}$ tiene en el tope de la ordenación de preferencias el poder, su felicidad debe resignarse debido a que se la da preferencia a la felicidad de $A_{2}$. Una solución de equilibrio entre preferencias en conflicto no es solución pues, precisamente, no satisface tales preferencias.

Puede parecer que este es un problema aislado que afecta a ciertas preferencias muy particulares como el poder y la autonomía, pero no es así. Se trata de un problema perfectamente general. La riqueza, por ejemplo, no es infinita. El Estado no puede otorgar poder adquisitivo a alguien sin mermar el de otras personas. El Estado no puede entregar grandes cantidades de dinero a todas las personas sin provocar el efecto de desvalorizar ese dinero. En vez de otorgar poder adquisitivo de manera masiva está reduciendo el poder adquisitivo de sus prestaciones de manera masiva y, con ello, no está satisfaciendo tal preferencia. Pero además sucede que, incluso si - per impossibile - el Estado tuviese recursos infinitos, no podría satisfacer estas preferencias. Cuando se quiere ser rico no se está pensando en alcanzar un nivel determinado de poder adquisitivo. Ser rico es algo comparativo, es tener más capacidad adquisitiva que los demás o que el promedio de las

un derecho humano, parte del ius cogens, ni el constituyente, ni un tratado internacional podrían modificarlo. 
personas. Un pobre de muchas de nuestras sociedades tiene un estándar de vida mucho más alto que un príncipe en el siglo IX. Un pobre del siglo XXI se siente pobre, sin embargo, porque comparativamente tiene menos poder adquisitivo que muchas otras personas o que el promedio. Entonces sucede que un Estado no puede hacer que todas las personas sean ricas. Solo puede hacer a alguien rico al costo de hacer a alguien pobre. Algo semejante sucede con la fama, con la belleza y con la inteligencia. Cuando son parte de las preferencias de las personas se trata de ventajas de carácter comparativo. Quien quiere ser inteligente, quiere ser más inteligente que el resto, o que el promedio. Quien quiere ser bella, quiere ser más bella que el resto, o que el promedio. Si el Estado concede belleza por igual a todas las personas, no está satisfaciendo tales preferencias. Tampoco las estaría satisfaciendo si entrega inteligencia por igual a todas las personas. Algo semejante se podría decir de la fama. Una sociedad donde todos son igualmente famosos es una sociedad donde es famoso.

Cuando se trata del placer uno podría pensar que la situación no es tan complicada. Después de todo, ¿qué problema habría en entregar la misma porción de drogas a todas las personas? ¿O qué problema existiría en conceder una máquina de experiencias a toda persona? El problema radica en que hay muy diversos tipos de placer. Para algunos placeres pueden no surgir dificultades de un tipo análogo a las indicadas arriba, pero el placer que busca un sádico, un psicópata o un pedófilo exige someter a otras personas a experiencias dolorosas y dañinas. Ningún Estado civilizado estaría dispuesto a facilitar tales placeres pues afecta la felicidad de otras personas. El problema, nuevamente, es que para establecer estas restricciones, el Estado estaría poniendo la felicidad de ciertas personas por encima de la felicidad de otras. La felicidad de los niños, por ejemplo, sería conseguida al precio de negar la felicidad de los adultos pedófilos. Así como alguien puede negarse a conceder placer a un sádico pues es al costo de su propia felicidad, el sádico podría reclamar al Estado que su propia felicidad se está sacrificando para la felicidad de otros.

Uno estaría aquí inclinado a sostener que estos problemas son un indicio de que las teorias externalistas de la felicidad son malas teorias de la felicidad. Estoy de acuerdo. No creo que ninguna de estas teorias sea medianamente razonable. Para lo que interesa en este trabajo, sin embargo, importa destacar que bajo estas condiciones no puede haber un derecho subjetivo fundamental a la felicidad inteligible. La situación es la siguiente: si hubiese un derecho subjetivo fundamental a la felicidad, entendida de un modo externalista, no podría respetarse tal derecho pues un derecho fundamental debe ser de todas las personas, y no es posible satisfacerlo para todas las personas. Un derecho que, por su mismo contenido, no puede ser satisfecho, no es ningún derecho. Se trataría de una situación análoga a la de un derecho para que se realice el estado de cosas de ser el caso que $p$ y no ser el caso que $p$. El supuesto estado de cosas de ser el caso que $p$ y no ser el caso que $p$ es imposible. Nadie puede tener un derecho subjetivo para obtener un estado de cosas imposible, pues nadie podria estar obligado a realizar un estado de cosas imposible. Aquí, de un modo semejante, el Estado estaría asumiendo la obligación de hacer que todas las personas sean felices —entendida la felicidad de 
un modo externalista-. Pero tal cosa es imposible por los motivos indicados. Entonces, no puede haber tal obligación, y tampoco puede haber derecho correlativo.

\subsection{Derecho a una felicidad interna a la voluntad}

Resta considerar el caso de un derecho a la felicidad entendida de un modo internalista. En las concepciones internalistas la felicidad está constituida —en todo o en parte- por actos voluntarios de la persona. Es esencial a un acto voluntario de la persona $A$ que solamente $A$ puede realizarlo. Nadie diferente de $A$ puede realizar un acto voluntario de $A$ por representación o de manera vicaria. Esto genera un problema básico para la inteligibilidad de un supuesto derecho subjetivo fundamental a la felicidad desde una perspectiva internalista. Un derecho de este tipo debería ser un complejo de elementos hohfeldianos. Estos complejos tienen en su base reclamos / derechos. Pero no hay aquí ningún tipo de reclamo / derecho que inteligiblemente pudiesen reclamar las personas al Estado. No hay ninguna prestación que el Estado pudiese dar para asegurar la felicidad de las personas, pues eso requeriría que este suplantase la actividad libre de esas personas. Cualquiera sea esa acción del Estado, ya no sería una acción libre de nadie. ¿Qué tipo de prestación podría dar el Estado que consistiese en la actividad del alma en conformidad con la virtud? ¿Cómo podría suplantar la virtud de alguien? ¿Cómo podría otorgar una prestación que consistiese en una amistad, o en un acto de conocimiento, o en un acto de apreciación de la belleza? ¿Podría un Estado suplantar la vida de oración de una persona? Al no haber ningún elemento hohfeldiano posible de primer nivel en este caso, tampoco lo hay de segundo nivel.

Esto no impide que el Estado pueda asumir la obligación de contribuir a la conformación de las condiciones necesarias para el despliegue de estos actos de libertad, pero las condiciones necesarias de tales actos no son esos actos. El Estado puede contribuir, por ejemplo, con la preservación de cierto patrimonio artístico que pueda luego ser apreciado estéticamente por las personas. Puede contribuir a financiar la investigación que permita el conocimiento de la verdad. Puede generar las condiciones de paz social en las que puedan desplegarse el amor, la amistad y las restantes relaciones humanas. Puede generar las condiciones sociales en las que los actos de culto religioso puedan ser desarrollados sin perturbación. Ninguna de estas cosas, sin embargo, cuenta como sustituto de los actos libres de las personas de contemplación de la verdad, de apreciación de la belleza, de amistad o de religión. El derecho que pueda reclamar alguien a estas contribuciones del Estado no es tampoco un derecho a la felicidad, pues no es la felicidad lo que se otorga con las prestaciones. Perfectamente se puede sostener que toda la acción del Estado debe estar dirigida a generar estas condiciones necesarias para la felicidad de las personas, pero no está al alcance del Estado la felicidad de las personas. ${ }^{27}$

27 Esto ha sido correctamente planteado por Finnis, quien sostiene que la gramática de los derechos fundamentales es una traducción jurídica de las dimensiones básicas del bien humano y de la tarea del Estado respecto de ellos. John FinNis, Natural Law and Natural Rights, op. cit., pp. 210-218; Aquinas. Moral, Political, and Legal Theory, Oxford, Oxford University Press, 1998, pp. 132-186. 
Tal vez en este punto se pudiese pensar que el derecho a la felicidad — si es que la felicidad se entiende de un modo internalista - podría ser concebido fundamentalmente como una libertad. De acuerdo con el esquema hohfeldiano se podría pensar en un derecho que estuviese integrado por la libertad de las obligaciones que pudiesen obstruir el despliegue de nuestros actos libres en los que consiste la felicidad de acuerdo con esta perspectiva. Uno podría suponer que esta libertad ha de estar acompañada de un reclamo / derecho respecto de toda persona para que no realice acciones que puedan perturbar este despliegue. Tratándose de un derecho fundamental debería ser de toda persona y estaría también acompañado de poderes restringidos y de inmunidades extendidas, tal como se explicó. Solo el constituyente o varios Estados, mediante un tratado, podrían modificar estas libertades y reclamos / derechos. ${ }^{28}$ Se trataria de libertades y reclamos / derechos que no admiten ser cedidos, renunciados, transferidos o transados a diferencia de lo que sucede con un derecho de carácter patrimonial. El derecho a la felicidad sería entendido así como un derecho a "perseguirla", tal como aparece en la Declaración de Independencia de Estados Unidos. ${ }^{29}$ ¿Cómo podría, sin embargo, ser perturbada esta libertad para perseguir la felicidad mediante nuestra propia libertad? Se haria con lesiones a la vida o a la integridad física o psíquica de las personas; con impedimentos a la libertad para educarse (y enseñar); con impedimentos a la libertad personal, por ejemplo, mediante detenciones arbitrarias; mediante intromisiones indebidas a la privacidad; mediante impedimentos a la libertad de religión; mediante impedimentos a asociarse con otras personas para el desarrollo de proyectos comunes; mediante lesiones a la propiedad, que asegura ciertos espacios de libertad y para gozar de los frutos del propio trabajo. Parece razonable proteger a las personas de estas lesiones y perturbaciones. La protección respecto de estas lesiones e intromisiones, sin embargo, es lo que ya está garantizado por los derechos fundamentales contenidos en casi todas las normas constitucionales y en los instrumentos internacionales de derechos humanos. Un derecho a la felicidad entendido de este modo sería, por tanto, redundante. No es extraño que suceda esto. Sería muy irrazonable suponer que todo el desarrollo de nuestras instituciones politicas y jurídicas no tuviese nada que ver con lo que, según nuestra mejor evidencia, es la vida buena y contribuye o perturba una vida buena. Las garantias fundamentales ya contenidas en nuestras constituciones pretenden estar cautelando la libertad para perseguir la felicidad. Esto es todo lo que el Estado razonablemente puede proponerse respecto de la felicidad. Tal vez

28 O ni siquiera ellos, si es que este derecho se considera parte del ius cogens, tal como se ha indicado ya más arriba.

29 La Declaración de Independencia de Estados Unidos señala textualmente: "We hold that these truths are self-evident, that all men are created equal, that they are endowed by their Creator by certain inalienable Rights, that among these are Life, Liberty, and the pursuit of Hapiness" (énfasis agregado). Un evaluador anónimo ha hecho notar que también son relevantes aquí otros antecedentes comparados. En la Constitución Nacional de Colombia se consagra en su artículo 16 que: "Todas las personas tienen derecho al libre desarrollo de su personalidad sin más limitaciones que las que imponen los derechos de los demás y el orden jurídico”. La Constitución Española señala en su artículo 10, núm. 1, que: "La dignidad de la persona, los derechos inviolables que le son inherentes, el libre desarrollo de la personalidad, el respeto a la ley y a los derechos de los demás son fundamento del orden politico y de la paz social". Lo que aparece en las constituciones colombiana y española como "libre desarrollo de la personalidad" puede entenderse como una libertad fundamental para no ser impedido el despliegue de la actividad libre en que consiste la felicidad. 
en este punto uno podría sostener que a pesar de que la protección de esta libertad fundamental es algo que ya se hace con las garantías usuales, es conveniente la introducción de un derecho a la felicidad en estos términos - esto es, como una libertad hohfeldiana - pues es una reafirmación de la función del Estado para la vida buena de las personas. ${ }^{30}$ No obstante, debe notarse aquí que se trataría de una reafirmación de contenidos normativos que ya son parte del sistema jurídico. Los Estados no están, por tanto, omitiendo una garantía fundamental al no establecer tal derecho a la felicidad.

Resulta así que, en el mejor de los casos, un derecho a la felicidad, entendida de modo internalista, sería redundante. Esto es, entendido como una libertad fundamental de perseguir la felicidad, el contenido del derecho a la felicidad estaría ya recogido en las garantías tradicionales.

\section{CONCLUSIONES}

Se ha examinado el contenido del concepto de un supuesto derecho a la felicidad. Para este examen se ha utilizado el esquema de Hohfeld en el que se distinguen reclamos / derechos, libertades, poderes e inmunidades. Si hay un derecho a la felicidad debería consistir en, al menos, alguno de estos elementos hohfeldianos. La situación habitual es que los derechos estén constituidos por un complejo de estos elementos. Resulta fundamental, también, considerar qué deba entenderse por felicidad. Esta es una cuestión filosóficamente muy disputada y desde muy antiguo. Se ha mostrado, sin embargo, que sin que sea necesario entrar en las cuestiones sustantivas, estas concepciones pueden ser agrupadas en dos grandes categorias: las teorias que conciben a la felicidad como estados, eventos u objetos no constituidos por actos libres de la persona, y las teorías que conciben a la felicidad como constituida por actos libres de la persona. Hay dificultades de principio para un supuesto derecho a la felicidad bajo cualquiera de estos dos supuestos.

De acuerdo con la primera concepción de la felicidad, el Estado debería estar obligado a entregar ciertas prestaciones a todas las personas para asegurar cosas como el placer, la riqueza, la fama, la belleza o la inteligencia. El problema surge aquí porque es imposible que el Estado pueda entregar tales cosas a todas las personas que están bajo su jurisdicción, ni aún si — per impossibile - tuviese recursos infinitos. Una obligación que requiera realizar algo imposible no es obligación. Y el derecho a algo imposible tampoco es derecho.

De acuerdo con la segunda concepción de la felicidad, el Estado debería estar obligado a entregar ciertos actos libres de las personas. Pero es imposible para el Estado, como para cualquier persona que no sea el agente, realizar tales actos libres. La felicidad entendida de este modo está completamente fuera del alcance de la acción del Estado. Esto no impide que el Estado pueda tener como finalidad fundamental asegurar las condiciones necesarias para el ejercicio de la libertad

30 Debo esta acotación a un evaluador anónimo. 
de las personas en la consecución de la felicidad. Tampoco impide que se deban asegurar las libertades para perseguir la felicidad. Estas libertades, sin embargo, coinciden con las garantías fundamentales incorporadas desde hace tiempo ya en las constituciones y en los instrumentos de derechos humanos. Un derecho a la felicidad entendido en estos términos restringidos - como una libertad para perseguir la felicidad - sería, en el mejor de los casos, redundante. ${ }^{31}$

\section{BIBLIOGRAFÍA}

AввÀ, Giuseppe, Felicidad, vida buena y virtud, Barcelona, Ediciones Internacionales Universitarias, 1992.

AlEXY, Robert, Teoria de los derechos fundamentales, traducción y estudio introductorio de Carlos Bernal Pulido, Madrid, Centro de Estudios Políticos y Constitucionales, 2007.

ARISTÓTEles, Ética a Nicómaco, Introducción, traducción y notas de José Luis Calvo Martínez, Madrid, Alianza, 2001.

Boeri, Marcelo, Los estoicos antiguos, traducción, análisis y notas de Marcelo D. Boeri, Santiago, Editorial Universitaria, 2004.

Bronstein, John, Buccafusco, Christopher, Masur, Jonathan S. (eds.), Happiness and the Law, Chicago, The University of Chicago Press, 2015.

CRISP, Roger, "Well-Being”, en Ed Zalta (ed.), Stanford Encyclopedia of Philosophy, 2013, en http://plato.stanford.edu/entries/well-being/, fecha de consulta: 10 de octubre de 2015.

Edmundson, William A., An Introduction to Rights, Cambridge, Cambridge University Press, 2004.

Ferrajoli, Luigi, “Diritto fondamentali”, Teoria Politica 14 (2) (1998), pp. 3-33. Reimpreso como "Derechos fundamentales" en Antonio CABO, Gerardo Pisarello (eds.), Los fundamentos de los derechos fundamentales, Madrid, Trotta, 2001, pp. 19-56.

FERRAJOl, Luigi, “I fondamenti dei diritti fondamentali”, Teoria Politica 16 (3) (2000), pp. 41-113. Reimpreso como "Los fundamentos de los derechos fundamentales”, en Antonio CABo, Gerardo Pisarello (eds.), Los fundamentos de los derechos fundamentales, Madrid, Trotta, 2001, pp. 287-381.

FinNIS, John, Fundamentals of Ethics, Washington, Georgetown University Press, 1983.

Finnis, John, Aquinas. Moral, Political, and Legal Theory, Oxford, Oxford University Press, 1998.

31 Este trabajo ha sido redactado en ejecución del proyecto de investigación Interdisciplina 3/2014 de la Vicerrectoría de Investigación de la Pontificia Universidad Católica de Chile. Agradezco los útiles comentarios y sugerencias de un par de evaluadores anónimos de esta revista. 
FinNis, John, Natural Law and Natural Rights, 2 ed., Oxford, Oxford University Press, 2011.

Frankena, William, Ethics, 2 ed., Englewood Cliffs, Prentice Hall, 1973.

Harel, Alon, "Theories of Rights", en Martin P. Golding, William A. Edmundson (eds.), The Blackwell Guide to the Philosophy of Law and Legal Theory, Oxford, Blackwell, 2005, pp. 191-206.

Hart, H. L. A., The Concept of Law, Second Edition with a Postcript, Penelope A. Bulloch, Joseph Raz (eds.), Oxford, Clarendon Press, 1994.

Haybron, Daniel M., The Pursuit of Unhappiness. The Elusive Psychology of WellBeing, Oxford, Oxford University Press, 2008.

Hohfeld, Wesley N., "Some fundamental legal conceptions as applied in judicial reasoning”, en Yale Law Journal 23 (1913). Reimpreso en Fundamental legal conceptions as applied in judicial reasoning and other legal essays, Cook, Walter Wheeler (ed.), New Haven, Yale University Press, 1923, pp. 23-64.

Hurka, Thomas, Perfectionism, New York, Oxford University Press, 1993.

Ivison, Duncan, Rights, Stocksfield, Acumen, 2008.

Kamm, F. M., "Rights", en Jules L. Coleman, Kenneth Einar Himma, Scott J. Shapiro (eds.), The Oxford Handbook of Jurisprudence and Philosophy of Law, Oxford, Oxford University Press, 2004, pp. 476-513.

KAnE, Robert, "Introduction: The Contours of Contemporary Free Will Debates", en Robert Kane (ed.), The Oxford Handbook of Free Will, Oxford, Oxford University Press, 2002, pp. 3-41.

Kramer, Matthew H., Simmons, N. E., Steiner Hillel, A Debate Over Rights. Philosophical Enquiries, Oxford, Oxford University Press, 1998.

KRAUT, Richard, What is good and why, Cambridge, Harvard University Press, 2007.

Nozick, Robert, Anarchy, State, and Utopia, Oxford, Blackwell, 1974.

PÉREZ Luño, Antonio-Enrique, La tercera generación de derechos humanos, Cizur Menor, Thomson Aranzadi, 2006.

Posner, Eric A., Sunstein Cass R. (eds.), Law and Happiness, Chicago, The University of Chicago Press, 2010.

Rainbolt, George W., The concept of rights, Dordrecht, Springer, 2006.

San Agustín, Confesiones, traducción, notas e introducción de Gustavo Piemonte, A., Buenos Aires, Colihue, 2006.

Santo Tomás de Aguino, Summa theologiae, cura et studio Petri Caramello cum texto ex recensione leonina, Roma, Marietti, 1952.

van Inwagen, Peter, "Free will remains a mystery", en Robert Kane (ed.), The Oxford Handbook of Free Will, Oxford, Oxford University Press, 2002, pp. 158-177. 
Wellman, Carl, An Approach to Rights. Studies in Philosophy of Law and Morals, Dordrecht, Springer, 1997.

Wenar, Leif, "The analysis of rights", en Matthew H. Kramer, Claire Grant, Ben ColBurn, Antony Hatzistavrou (eds.), The Legacy of H. L. A. Hart: Legal, Political, and Moral Philosophy, Oxford, Oxford University Press, 2008, pp. 251-274.

WenAR, Leif, "Rights", en Ed ZaLTA (ed.), The Stanford Encyclopedia of Philosophy, 2015, en http://plato.stanford.edu/entries/rights/, fecha de consulta: 30 de septiembre de 2015. 